Kunstausstellung der Schweizer Ärzte und Ärztinnen in Murten

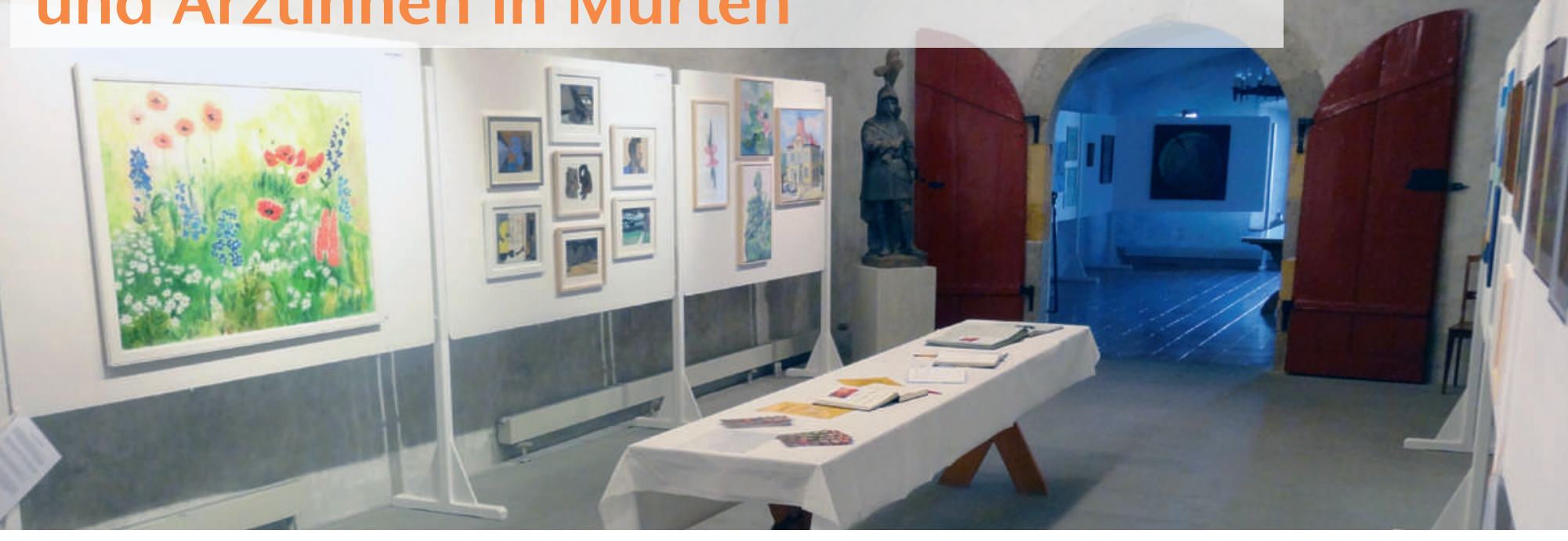

\section{Ruedi Grüring}

Präsident Kunstausstellung der Schweizer Ärzte / Salon des Médecins Suisses

Korrespondenz: Dr. med. Ruedi Grüring Flurweg 18

CH-3800 Matten b. Interlaken Tel. 0338231025

info[at]aerzte-kunst.ch
Wie die Mehrheit seiner Aktivmitglieder hat der Verein «Kunstausstellung der Schweizer Ärzte / Salon des Médecins Suisses» in diesem Jahr das Rentenalter erreicht, wurde er doch schon 1948 gegründet mit der Absicht, dass kunstschaffende Kolleginnen und Kollegen wie auch deren Partner und Partnerinnen ihre Werke einer breiteren Öffentlichkeit zeigen können.

Das ehrwürdige Alter bedeutet aber nicht, dass wir nun weniger aktiv sind. An der diesjährigen traditionellen Ausstellung in Murten, die vom 13. Juli bis 3. August im Rathauskeller durchgeführt wurde, zeigten 23 Mitglieder ihre Werke, und über 400 Inter essierte haben die vielfältige Ausstellung besucht.

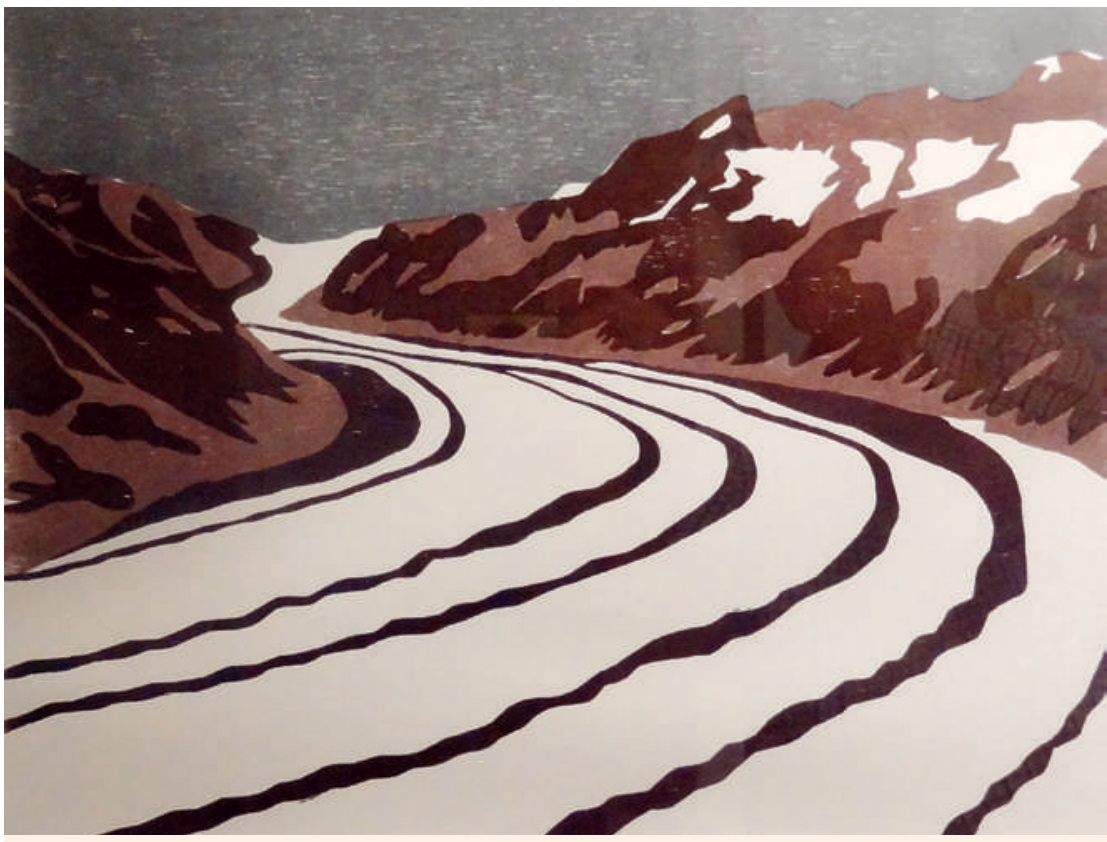

Peter Schlup, «Aletsch», Farbholzschnitt, 2011.
Für viele von uns bedeutet die schöpferische Tätigkeit Entspannung und Erholung, das Erleben einer positiven Auszeit. $\mathrm{Zu}$ welch ansprechenden und vielfältigen Resultaten dies führt, zeigte der Rundgang durch die Ausstellung:

Neben einigen Raku-Skulpturen waren Aquarelle, Arbeiten mit Acryl und Gouache auf Papier oder Leinwand, Ölgemälde und Collagen ausgestellt. Aber auch Farbholzschnitte, graphische Arbeiten mit Bleistift und Tusche und besonders originelle Werke auf Altholz mit Acryl, Foto und Metall waren vertreten. Als Motive dienen oft Ferienerinnerungen an Landschaften und Städte, Stillleben und Porträts bis hin zu ganz abstrakten Werken.

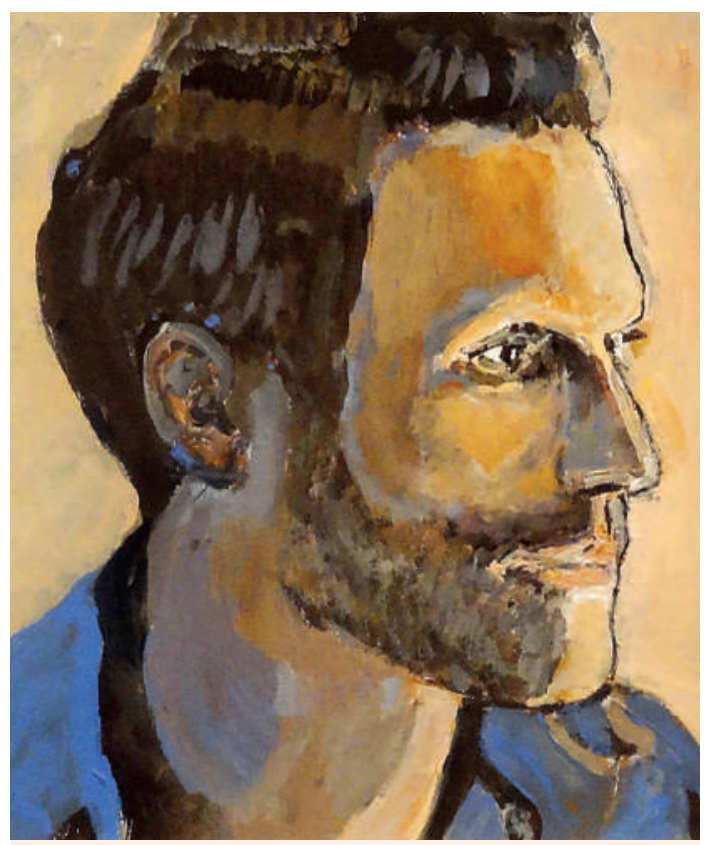

Koni Bigler, «Porträt Thomas Bigler», Acryl, 2013. 


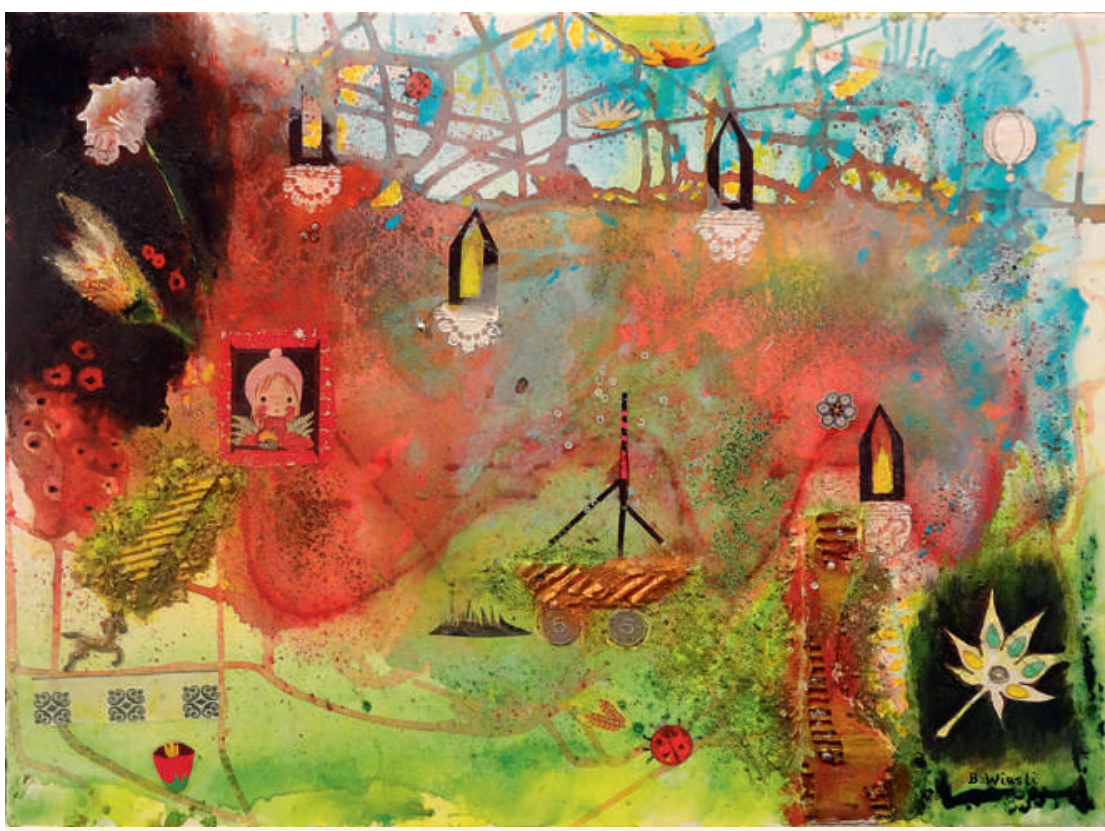

Bernhard Wiesli, «Träume», Acryl, experimentell, 2013.

Auch wenn sich für einige Aktivmitglieder ihr schöpferisches Tun im Ruhestand fast zu einem weiteren Beruf nach der Medizin entwickelt hat, soll es weiterhin ein Steckenpferd für alle bleiben, das jeder nach seinen Fähigkeiten pflegen kann, so wie es Henry van Dyke einmal formuliert hat: «Nutze die Talente, die du hast. Die Wälder wären sehr still, wenn nur die begabtesten Vögel sängen.»

Die nächste Ausstellung in Murten ist bereits für den 12. Juli bis 2. August 2014 geplant, neue Aktivwie auch Passivmitglieder sind herzlich willkommen, ein Besuch auf unserer Homepage (www. aerzte-kunst.ch) lohnt sich.

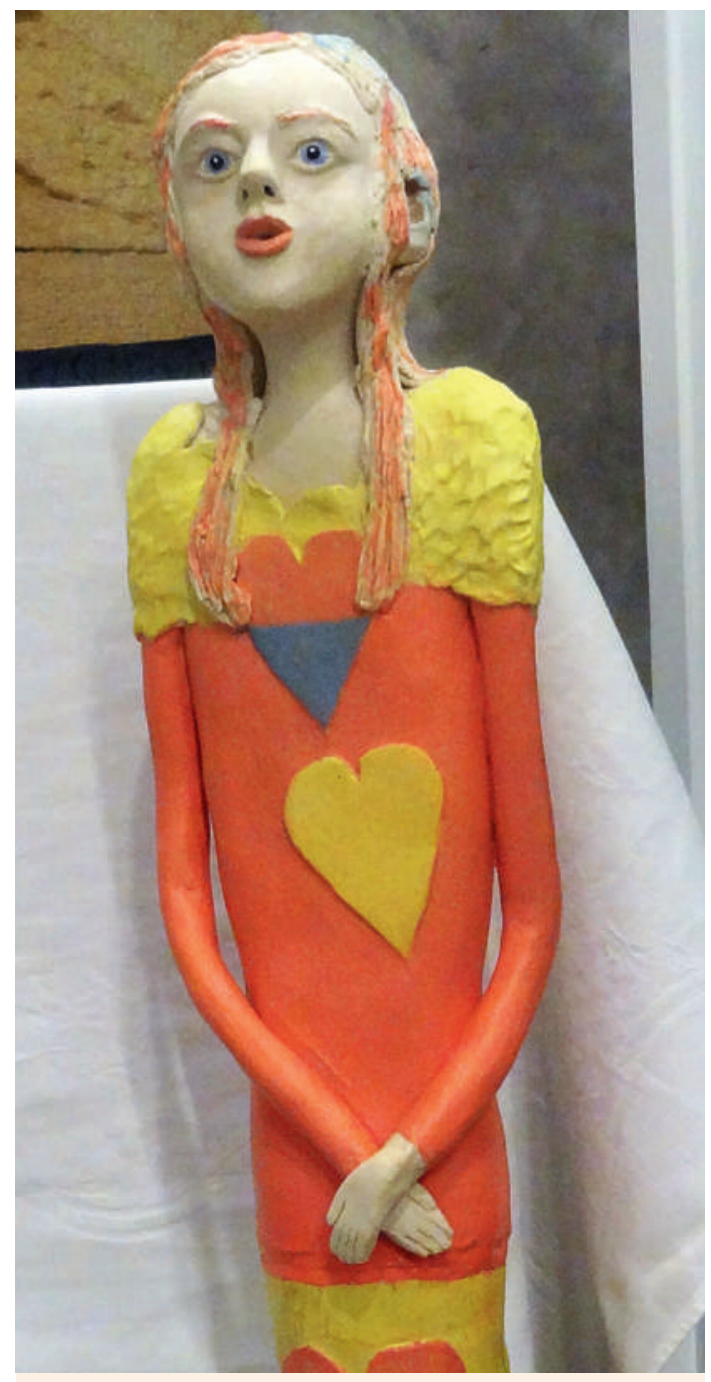

Monika Wiesli, «Herzli-Meitschi», Skulptur, 2013.

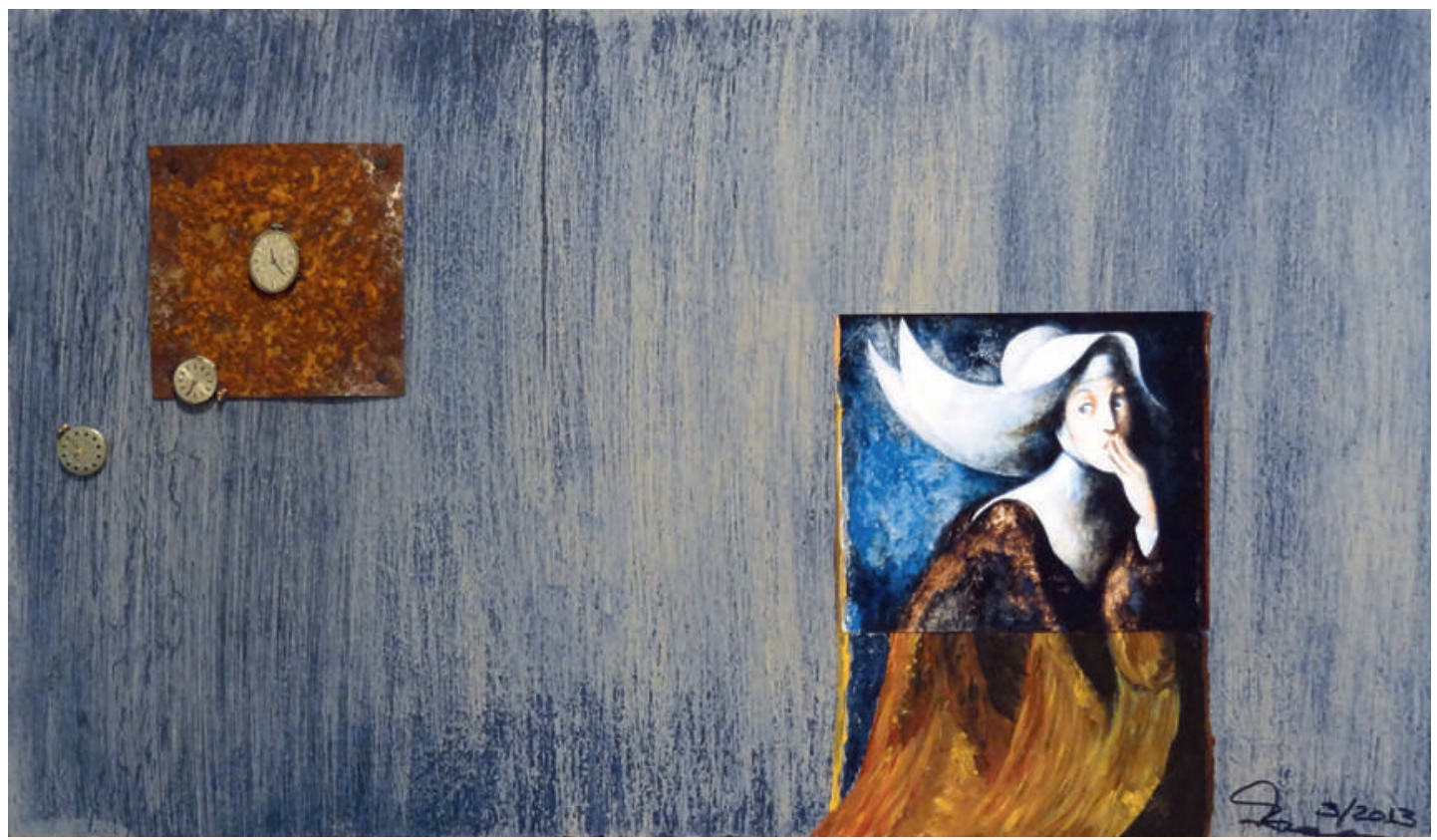

Cordula Boose, «Die Zeit läuft», Altholz, Acryl, Foto, Metall, 2013. 